\title{
CORRIGENDUM \\ ON THE DISCREPANCY OF COLORING FINITE SETS
}

\author{
D. HAJELA \\ Bellcore \\ Morristown, New Jersey 07960
}

There is a reference which has been inadvertantly omitted from the above paper which appeared in Vol. 13, No. 4, (1990), pages 825-827. The omission is corrected as follows:

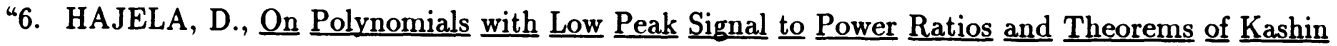
and Spencer, submitted to Advances in Applied Mathematics, 1989."

\section{ON SEMI-HOMEOMORPHISMS, \\ INTERNAT. J. MATH. \& MATH SCI. 13(1990) 129-134}

\section{J.P. LEE}

\author{
Department of Mathematics \\ State University of New York, College of Old Westbury \\ Old Westbury, NY 11568
}

Corollary 5 is false because of an incorrect argument used in the proof of Proposition 1. A Mathematical Reviews reviewer pointed out the following counterexample to both of these results. Take $\mathbb{R}$ (the reals) with the Sorgenfrey topology, let $Y$ be $\mathbb{R}$ with the topology given by the base $B=\left\{\left[w_{1}, w_{2}\right): w_{1}, w_{2} \in \mathbb{Q}, w_{1}<w_{2}\right\}$ and let $f: X \rightarrow Y$ be the identity. Such an $f$ is one-to-one, semi-open and continuous but not iresolute

Further, the following is a counterexample to Lemma 9 (and hence Corollary 10$)$. Let $(\mathbb{R}, \mathcal{D})$ and $(\mathbb{R}, \mathcal{T}$ ) be spaces, where $\mathcal{D}$ is the discrete topology and $\mathcal{T}=\{(a,+\infty): a \in \mathbb{R}\} \cup\{\phi, \mathbb{R}\}$ and let $f: X \rightarrow Y$ be the identity. Clearly, $f$ is not somewhat open. 


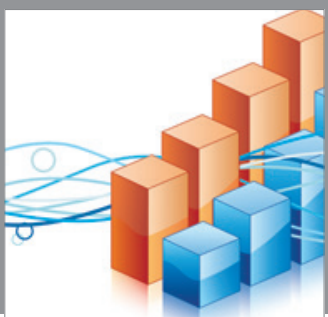

Advances in

Operations Research

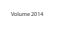

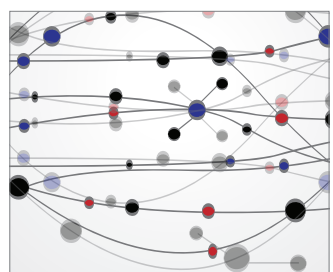

\section{The Scientific} World Journal
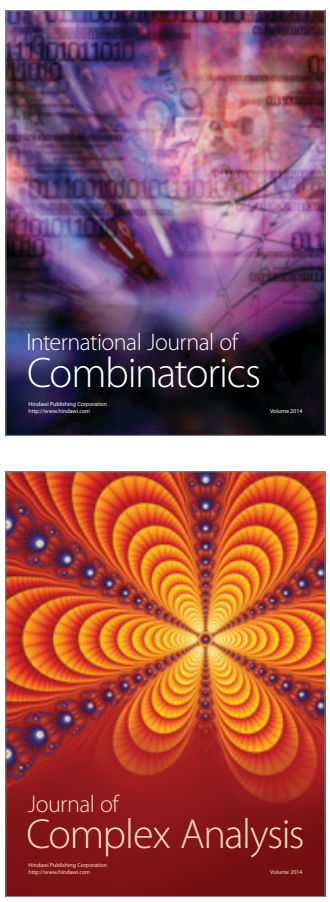

International Journal of

Mathematics and

Mathematical

Sciences
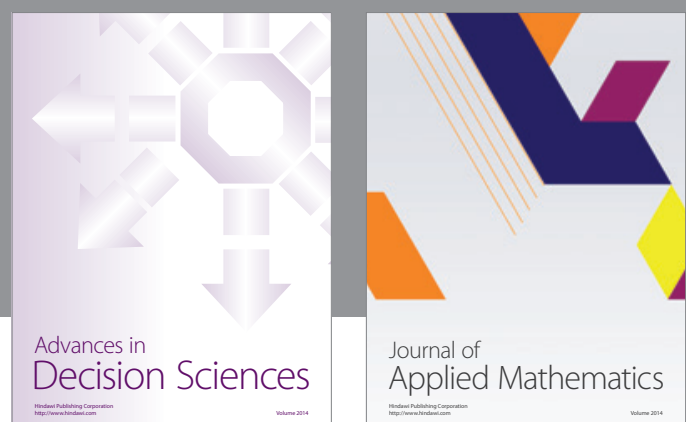

Journal of

Applied Mathematics
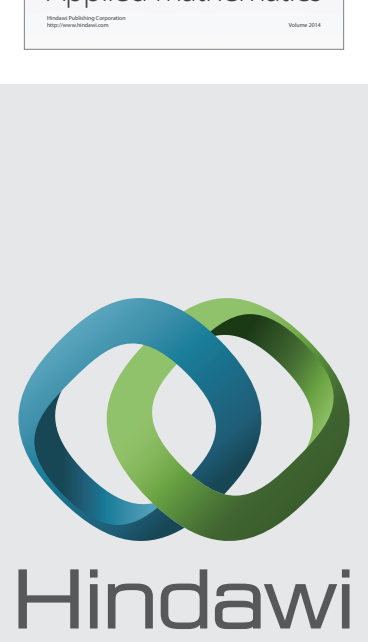

Submit your manuscripts at http://www.hindawi.com
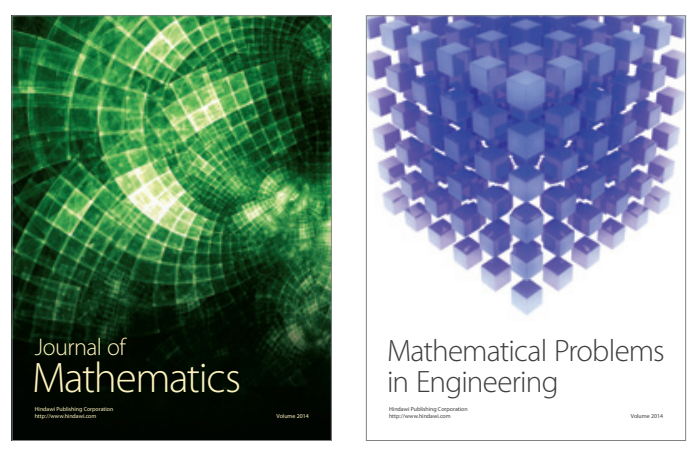

Mathematical Problems in Engineering
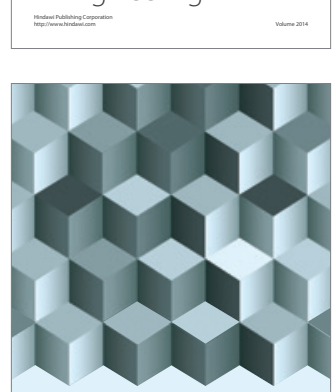

Journal of

Function Spaces
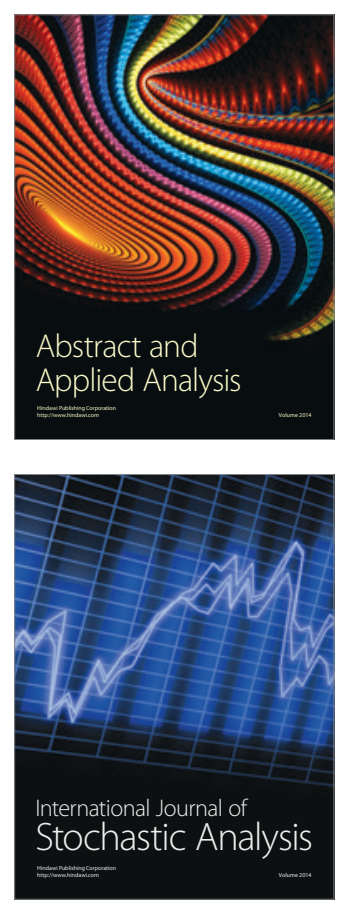

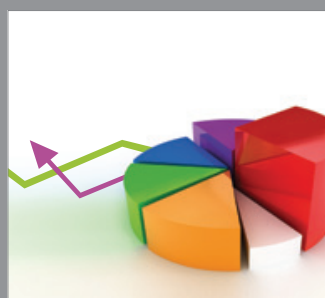

ournal of

Probability and Statistics

Promensencen
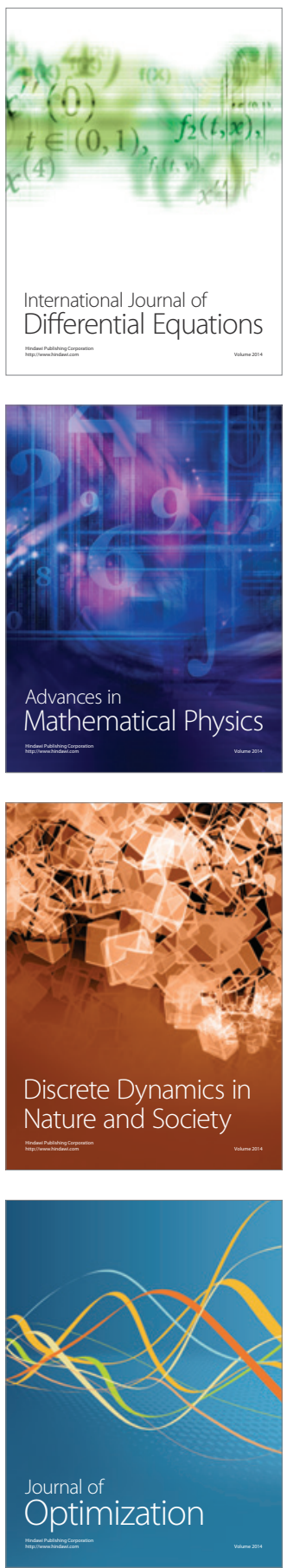